\section{MEDIOS DE COMUNICACIÓN IMPRESOS Y REALIDAD AUMENTADA, UNA ASOCIACIÓN CON FUTURO}

\author{
María Dolores Meneses Fernández \\ Universidad de La Laguna \\ dmeneses@ull.edu.es \\ Jorge Martín Gutiérrez \\ Universidad de La Laguna \\ jmargu@ull.edu.es
}

Cómo citar este artículo/Citation: Meneses Fernández, M. D. y Martín Gutiérrez, J. (2016). "Medios de comunicación impresos y realidad aumentada, una asociación con futuro". Arbor, 192 (777): a292. doi: http://dx.doi.org/10.3989/ arbor.2016.777n1008

Recibido: 20 enero 2014. Aceptado: 25 mayo 2015.

RESUMEN: La Realidad Aumentada es una tecnología de visualización novedosa que va afianzándose en numerosos campos profesionales y académicos. Permite recrear situaciones inmersivas, superponiendo a la realidad física otras virtuales. Su versatilidad y espectacularidad hace que prolifere su uso en periodismo y publicidad. Los autores vienen desarrollando, durante los últimos años, estudios sobre la percepción y usabilidad de esta tecnología, prestando interés especial a su aprovechamiento en medios impresos, un sector de la industria editorial en situación frágil que debe considerar el potencial que le ofrecen las tecnologías emergentes. La metodología aplicada se basa en cuestionarios y encuestas realizados a futuros profesionales de la comunicación, tras demostraciones participativas con esta tecnología. Los resultados cuantitativos obtenidos fueron tratados estadísticamente. La interpretación posterior permite concluir que estamos ante una tecnología valorada positivamente y con gran potencial en el ámbito de la comunicación social.

PALABRAS CLAVE: realidad aumentada; periodismo impreso; convergencia digital; periodismo inmersivo; competencias tecnológicas.

\section{PRINTING NEWSPAPERS AND AUGMENTED REALITY. A VIABLE PARTNERSHIP}

Copyright: (c) 2016 CSIC. Este es un artículo de acceso abierto distribuido bajo los términos de la licencia Creative Commons Attribution-Non Commercial (by-nc) Spain 3.0.

ABSTRACT: Augmented Reality (AR) is an innovative display technology that is finding applications in various academic disciplines and professional settings. AR can be used to create immersive experiences by overlaying virtual objects over realworld environments. Its versatility and astonishing capabilities have led to its widespread use in journalism and advertising. The authors of this paper have been researching perceptions and usability of AR for several years, focusing particularly on print media, a publishing sector whose precarious situation means it needs to consider the potential of emerging technologies. The methodology is based on questionnaires and surveys to gather data from future communications professionals, following interactive demonstrations of AR. The quantitative data obtained was then processed statistically. Subsequent data analysis revealed that AR is viewed positively by respondents, and seen to hold significant potential for the needs of the communications industry.

KEYWORDS: augmented reality; print newspaper; digital convergence; immersive journalism; technological skills. 


\section{INTRODUCCIÓN}

Las tecnologías de la información y la comunicación (TIC) se caracterizan por su constante desarrollo y evolución. En el caso de la Realidad Aumentada (RA, del inglés Augmented Reality o AR), las posibilidades que ofrece en el campo de las Ciencias Sociales y Humanas están sobradamente contrastadas, desde el periodismo hasta el patrimonio cultural y el turismo (Lapointe, 2002). También otras disciplinas, como las ingenierías, diversas especialidades de la medicina y la psicología clínica encuentran en ella aplicaciones de gran utilidad pedagógica y profesional (Furht, 2011).

Revisiones previas de los autores muestran cómo, en Comunicación Social, las tecnologías de visualización permiten innovar, contribuyendo al desarrollo de las industrias que aglutinan: el periodismo impreso, la publicidad, el escaparatismo y el marketing. Centrándonos en el periodismo, los responsables de los medios impresos deben conocer estas tecnologías emergentes para aprovechar sus ventajas y adaptarse a un público cada vez más digitalizado, convergente y exigente.

Puede obtenerse una visión global de estas tecnologías gracias a Gartner y sus representaciones gráficas (http://www.gartner.com). En ellas se sitúa el punto de desarrollo de cada tecnología, desde las de más reciente aparición hasta las afianzadas en el mercado y con uso normalizado en la sociedad. La curva Hype Cycle, que Gartner actualiza periódicamente, es una gráfica con forma de curva gaussiana a lo largo de la cual se ubican las tecnologías emergentes, en función de la fase de evolución, de las cinco existentes, en la que está situada en cada momento (figura 1). Gartner es una empresa consultora sobre nuevas tecnologías, entre cuyos servicios está el análisis de la investigación y la información difundidas sobre las tecnologías de la información y la comunicación (TIC). Cada año publica el informe
Emerging Technology Hype Cycle, destinado a evaluar el grado de madurez, las perspectivas de negocio y la dirección futura de casi dos mil tecnologías y tendencias. En la gráfica de Gartner, la RA se encuentra en fase de 'caída en la desilusión' (Trough of disillusionment)'; si la supera, esta tecnología entrará en la rampa de consolidación, para luego establecerse en la meseta de productividad -como se observa en la figura 1 , en esa meseta están el reconocimiento de voz, el control de gestos y las tecnologías de impresión 3D-. Se trata de una tecnología joven en vías de asentamiento, con expectativas altas porque puede ser aplicada en ámbitos culturales, profesionales y económicos diversos, así como en modelos de negocio diferentes, tal y como los medios de comunicación han comenzado a informar de ella desde 2013 (fase Mass media hype begins). De hecho, los medios consideran a esta tecnología emergente una de las fundamentales en el Hype Cycle: Aumentando a los humanos con tecnologías (Human Augmentation).

La proliferación en medios impresos de contenidos periodísticos complementados con contenidos aumentados ${ }^{2,3}$, junto con la posición de la RA en la Hype Cycle, fundamentan este trabajo orientado a analizar la percepción que tienen de esta tecnología estudiantes de Comunicación Social.

\section{DESCRIPCIÓN DEL ESTUDIO Y EXPECTATIVAS}

La RA es una tecnología que combina los escenarios reales o físicos (los que podemos ver y tocar) que nos rodean con otros virtuales, visualizados -superpuestos a aquéllos- en una pantalla o con gafas (Space Glass, Google Glass, Moverio Glass). No debe ser equiparada a la realidad virtual. Algunos autores la denominan realidad mixta o complementada, dado que el usuario percibe la realidad circundante más lo virtual superpuesto.

Figura 1. Datos de las tecnologías emergentes correspondientes a Hype Cycle de julio de 2013 y 2015
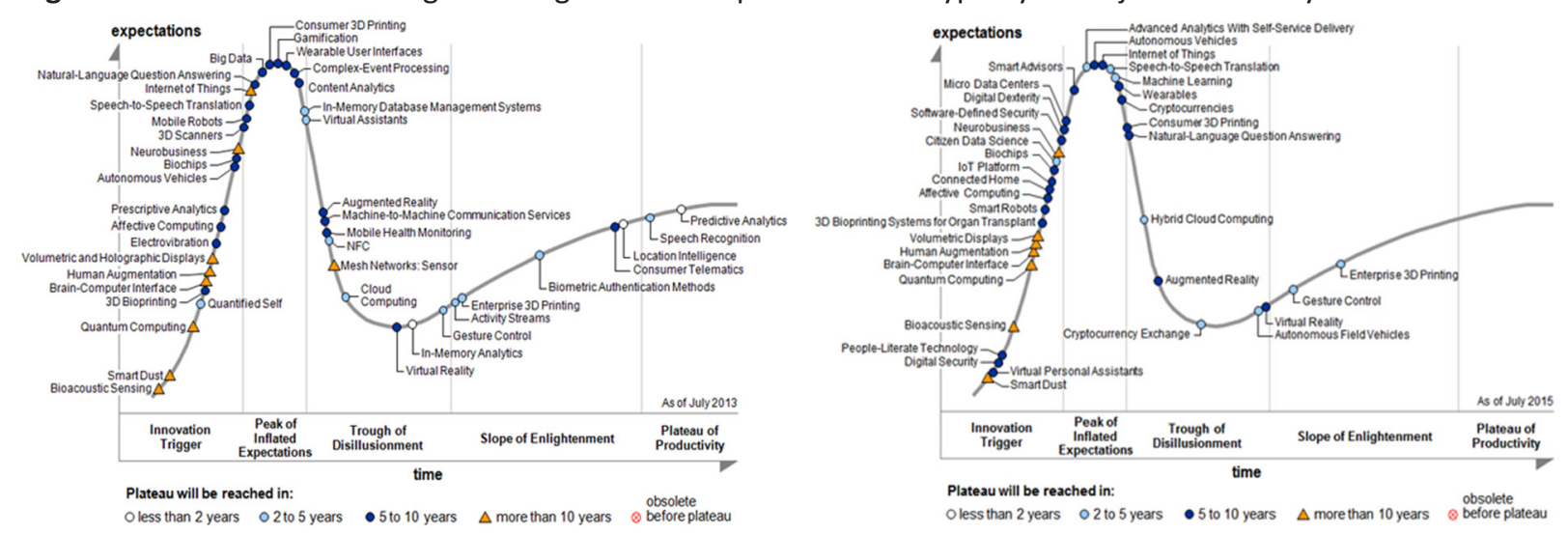

Fuente: gartner.com 
Las referencias de este estudio son los primeros casos de diarios y revistas de España y otros países que han ido incorporando, desde finales de 2009, la RA para ofrecer a sus audiencias contenidos aumentados (Meneses Fernández y Martín Gutiérrez, 2013). Tras esas primeras revistas Esquirre, Wallpapper, Grazia y Fotogramas, otras cabeceras como The Times, The Guardian o The Daily Telegraph en Reino Unido, LA Times en EEUU y METRO news en Canadá (figura 2), recurren a la RA para aumentar piezas con temática y géneros variados. Su aplicación al periodismo impreso potencia el componente de entretenimiento y proporciona contenidos adicionales mediante escenarios virtuales y audiovisuales que surgen de la plana impresa, recreando en la pantalla de un dispositivo situaciones inmersivas y contextos espaciales sorprendentes (véanse Recursos electrónicos en Bibliografía). Los editores de las cabeceras citadas han publicitado en la web y canal YouTube de sus empresas esta innovación ante la que se muestran optimistas, presentando los números aumentados como una primicia, e invitando a los lectores a disfrutar y divertirse con ellos. El caso de la editorial Newspaper Canadá va más allá al incorporar incluso una nueva experiencia interactiva ${ }^{4}$.

A. Bull (2013) considera que la aplicación de la RA y de los códigos QR puede ser una estrategia para afianzar un periodismo de marca híbrido (del inglés Brand Journalism), orientado a la comercialización de productos (y los contenidos periodísticos lo son), que renueva la forma de contar historias ante las nuevas necesidades de la publicidad, el marketing comunicacional y las relaciones públicas. En esa renovación narrativa tendente a involucrar al público desempeñan un papel clave las tecnologías de visualización interactivas, ya que permiten al usuario interactuar con la información visual.

La consulta por los autores de este trabajo de los contenidos impresos y aumentados publicados por las revistas y diarios citados, permite afirmar que la RA se está empleando para entretener y acercar al público los contextos noticiosos, asociando a lo impreso lo audiovisual, las reconstrucciones en 3D y acciones interactivas accesibles al lector mediante su dispositivo móvil. Por eso se revela como un recurso útil para el periodismo especializado, de servicio y de datos.

Según los informes de la Oficina de Justificación de la Difusión (OJD), de la empresa Información y control de publicaciones SA (http://www.ojd.es/), y el informe de la Asociación de Editores de Diarios Españoles (Observatorio mensual de la prensa

Figura 2. Noticia impresa del diario METRO Canadá y aplicación para dispositivos móviles METRO News Canadá con el modo de visualización de RA

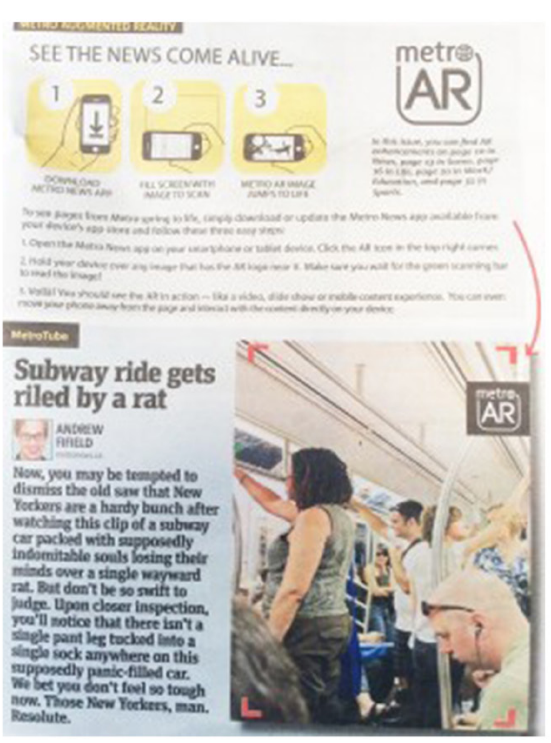

a) Noticia impresa en el diario METRO Canadá, con el logo identificativo de una noticia aumentada.

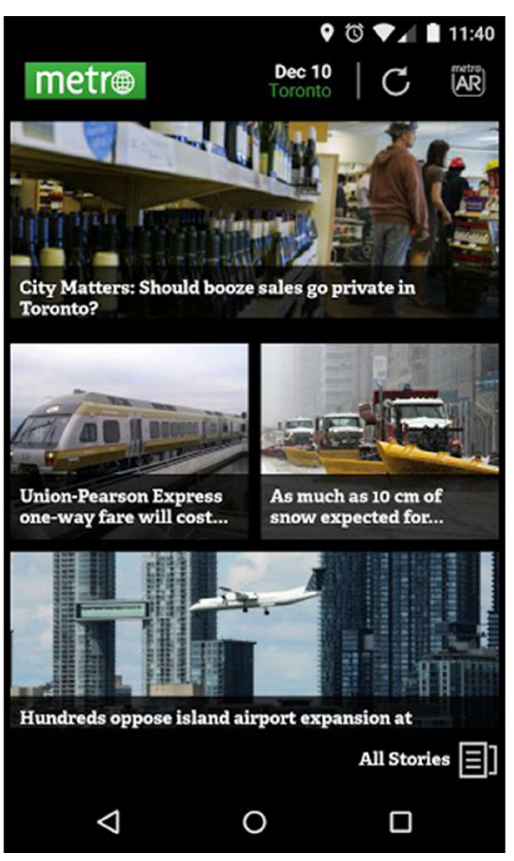

b) Aplicación móvil Metro News Canadá esquina superior, y botón para acceder al modo de RA.

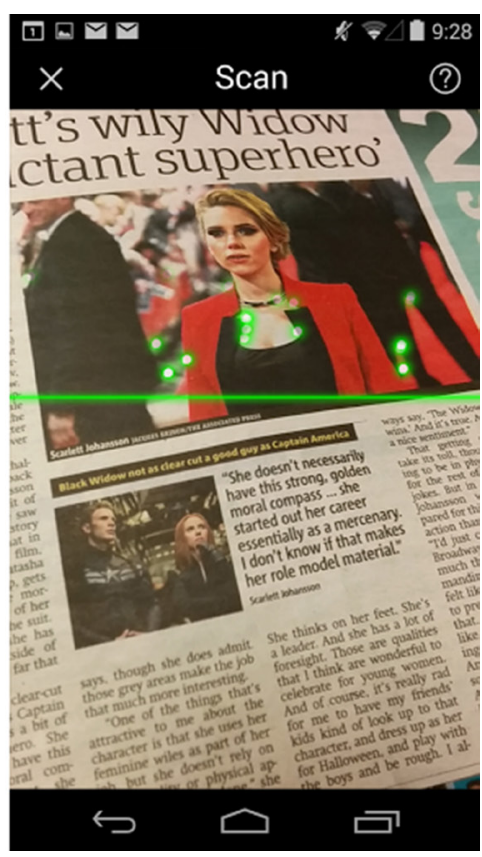

c) Escaneado de la noticia para aumentarla con contenidos audiovisuales. 
diaria), la prensa atraviesa una crisis severa como modelo de negocio, y aunque el periodismo digital no termina de afianzar su rentabilidad, las ventas y suscripciones indican que cada vez menos personas pagan por leer un periódico o revista en papel ${ }^{5}$. Los datos muestran caídas importantes mensuales en las ventas de los periódicos españoles (tabla I), hecho que en el panorama internacional se encuentra en la misma situación: una caída paulatina e importante de venta de periódicos, que se traduce en la reducción de ingresos por anunciantes $y$, en consecuencia, en la reducción de recursos humanos, causa de una grave crisis laboral en el sector periodístico (tabla II y figura 3).
El acceso gratis a las informaciones en Internet está extendido entre los sectores más jóvenes (Díaz Nosty, 2011), que son los consumidores a los que hay que fidelizar, pero que suelen carecer de capacidad adquisitiva para comprar periodismo impreso o digital.

A pesar de las debilidades de los medios digitales, estos han tomado fuerza frente a los impresos, abocados a desaparecer para muchos teóricos, empresarios y cargos ejecutivos (Estudios de Comunicación, 2013; AEDE, 2008-2013). Este nuevo escenario obliga a innovar para sobrevivir ante la oferta de contenidos gratis online. Es aquí donde la RA ofrece alternativas de modernización, sea cual fuere el futuro del periódico impreso (Meneses Fernández y Martín Gutiérrez, 2013).

Tabla I. Datos de ventas de diarios impresos españoles en el bienio 2011-2013

\begin{tabular}{|c|c|c|c|c|c|c|}
\hline \multicolumn{7}{|c|}{ Febrero 2011 - Febrero 2013} \\
\hline VENTAS & El País & El Mundo & $A B C$ & La Razón & Público & Gaceta \\
\hline Febrero & 308.745 & 183.168 & 127.047 & 76.413 & 58.078 & 35.698 \\
\hline Marzo & 267.437 & 159.561 & 128.188 & 68.747 & 42.712 & 36.263 \\
\hline Abril & 227.470 & 168.417 & 130.198 & 63.904 & 46.142 & 35.666 \\
\hline Mayo & 238.340 & 163.318 & 131.646 & 74.557 & 50.135 & 35.699 \\
\hline Junio & 209.114 & 171.014 & 120.179 & 62.961 & 53.965 & 34.423 \\
\hline Julio & 226.996 & 173.320 & 124.774 & 62.352 & 46.445 & 34.595 \\
\hline Agosto & 230.895 & 167.561 & 127.011 & 58.176 & 39.874 & 32.964 \\
\hline Septiembre & 230.289 & 194.210 & 138.796 & 66.020 & 37.468 & 29.565 \\
\hline Octubre & 221.070 & 185.206 & 128.463 & 81.746 & 40.518 & 30.174 \\
\hline Noviembre & 204.203 & 178.249 & 123.476 & 69.396 & 40.561 & 29.659 \\
\hline Diciembre & 206.491 & 178.254 & 116.476 & 59.639 & & 30.113 \\
\hline Enero & 220.140 & 176.578 & 131.816 & 65.269 & & 25.979 \\
\hline Febrero & 229.454 & 175.644 & 134.298 & 60.830 & & 24.361 \\
\hline Marzo & 211.508 & 173.354 & 128.699 & 54.541 & & 23.391 \\
\hline Abril & 210.690 & 162.091 & 127.432 & 66.607 & & 24.267 \\
\hline Mayo & 190.314 & 151.402 & 115.362 & 64.971 & & 21.522 \\
\hline Junio & 197.046 & 158.748 & 112.623 & 52.959 & & 20.898 \\
\hline Julio & 201.273 & 151.187 & 115.137 & 51.942 & & 20.542 \\
\hline Agosto & 189.422 & 141.961 & 107.865 & 48.167 & & 19.876 \\
\hline Septiembre & 197.490 & 153.925 & 121.708 & 61.884 & & 17.873 \\
\hline Octubre & 185.210 & 138.108 & 114.662 & 65.723 & & 17.040 \\
\hline Noviembre & 187.627 & 138.511 & 108.421 & 58.544 & & 15.946 \\
\hline Diciembre & 182.464 & 135.773 & 106.698 & 49.840 & & 17.051 \\
\hline Enero & 195.357 & 157.095 & 103.069 & 46.692 & & 14.538 \\
\hline Febrero & 201.075 & 165.674 & 106.404 & 66.804 & & 13.306 \\
\hline
\end{tabular}

Fuente: OJD. 
Tabla II. Datos de venta de diarios más suscripción de periódicos estadounidenses, periodo 2008-2014

\begin{tabular}{|l|c|c|c|c|c|c|c|}
\hline \multicolumn{1}{|c|}{ Newspaper } & $\mathbf{2 0 0 8}$ & $\mathbf{2 0 0 9}$ & $\mathbf{2 0 1 0}$ & $\mathbf{2 0 1 1}$ & $\mathbf{2 0 1 2}$ & $\mathbf{2 0 1 3}$ & $\mathbf{2 0 1 4}$ \\
\hline The Atlantic & 448.000 & 470.345 & 467.517 & 463.625 & 485.300 & 480.191 & 483.360 \\
\hline The Week & 509.000 & 513.512 & 517.187 & 528.406 & 551.658 & 565.567 & 574.370 \\
\hline The New yorker & 1.047 .000 & 1.044 .443 & 1.029 .742 & 1.041 .420 & 1.045 .565 & 1.055 .732 & 1.046 .977 \\
\hline The Economist & 767.000 & 812.031 & 828.181 & 844.577 & 844.016 & 824.885 & 783.353 \\
\hline Time & 3.374 .000 & 3.350 .835 & 3.313 .715 & 3.337 .308 & 3.278 .999 & 3.295 .217 & 3.284 .012 \\
\hline Newsweek & 2.720 .000 & 2.309 .416 & 1.578 .691 & 1.524 .989 & 1.527 .619 & N/A & N/A \\
\hline The Nation & N/A & N/A & N/A & 152.908 & 141.108 & 144.814 & 119.297 \\
\hline National Review & N/A & N/A & N/A & 170.390 & 164.034 & 157.686 & 147.808 \\
\hline Fortune & N/A & N/A & N/A & 843.416 & 844.164 & 851.308 & 843.914 \\
\hline Forbes & N/A & N/A & N/A & 933.859 & 927.379 & 936.992 & 931.228 \\
\hline The New Republic & N/A & N/A & N/A & N/A & 31.454 & 42.786 & 41.518 \\
\hline Rolling Stone & N/A & N/A & N/A & 1.480 .746 & 1.470 .451 & 1.468 .892 & 1.469 .223 \\
\hline Vanity Fair & N/A & N/A & N/A & 1.221 .363 & 1.215 .170 & 1.211 .334 & 1.214 .590 \\
\hline New York Magazine & N/A & N/A & N/A & 405.532 & 405.313 & 409.416 & 412.062 \\
\hline Bloomberg & N/A & N/A & N/A & 932.568 & 992.745 & 989.935 & 992.043 \\
\hline BusinessWeek Wired & N/A & N/A & N/A & 805.228 & 829.277 & 855.319 & 905.755 \\
\hline
\end{tabular}

Fuente: Alliance for Audited Media, AAM Audits and Publisher Statements.

Figura 3. Gráficos indicativos del desplome de ingresos publicitarios en los medios de comunicación y su repercusión en el empleo en los medios impresos. Datos de Estados Unidos

El derrumbe del empleo en los medios impresos de EEUU

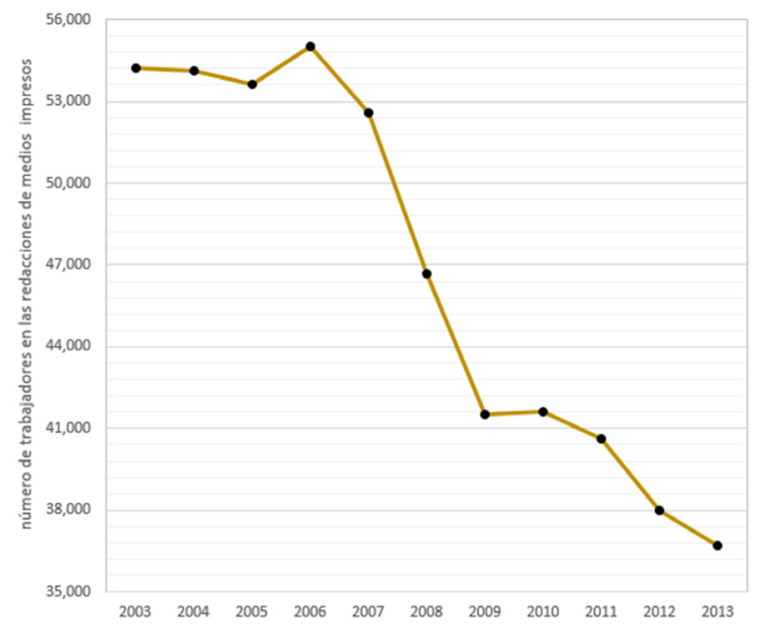

Fuente: Pew Research Center.

La Historia del Periodismo da cuenta de cómo la prensa se ha ido enfrentando a cada nuevo medio surgido del avance tecnológico; ahora, además, afronta la competencia de las pantallas de dispositivos móviles y de las gafas de visualización. Cada invento ha predicho su final, sin embargo ha sobrevivido ade-
Ingresos de medios de comunicación en EEUU por anunciantes

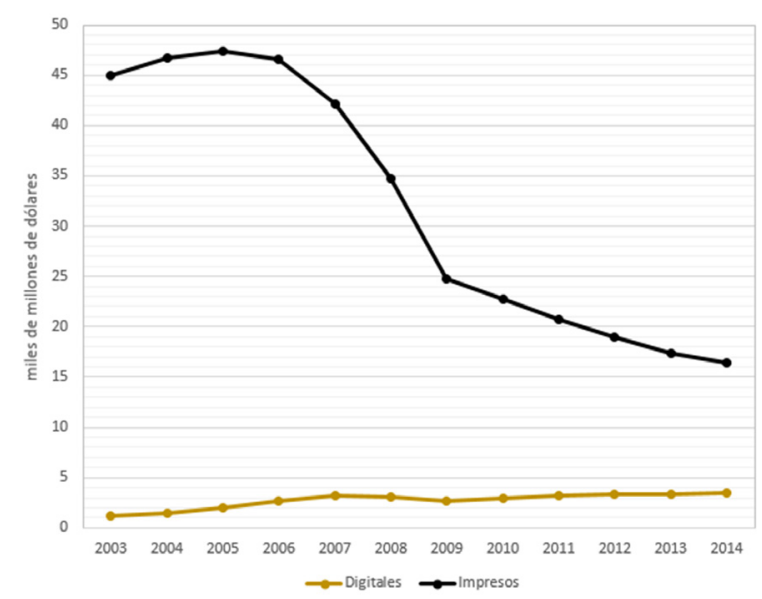

Fuente: Pew Research Center.

cuando sus contenidos y tratamientos, y confiando su diferenciación respecto de la inmediatez audiovisual mediante al análisis y la profundización. Hoy, aunque la convergencia digital difumine las fronteras entre medios, tratamientos y contenidos, la oferta impresa continúa estando ahí. 
En cualquier caso, la crisis de la industria editora obliga a innovar, y a experimentar estrategias narrativas y lectoras, buscando vías que vuelvan atractivos sus productos para lectores y anunciantes. De ello depende, tal y como han establecido los autores en trabajos previos, la renovación de la imagen del periodismo impreso.

El informe Libro Blanco de la Prensa Diaria (2015) presenta resultados en clave positiva. Este informe ofrece un análisis en profundidad del estado de la prensa española, destacando el repunte económico en 2014, un resultado similar a la cifra de 2011, tras tres años consecutivos de resultados negativos. El informe indica que la menor caída de venta de diarios respecto a años anteriores y una mejora de un $1 \%$ de los ingresos publicitarios han sido las razones de esta mejora de resultados. Además, se augura el mantenimiento de la audiencia y una esperada mejora del $5 \%$ en los ingresos publicitarios, lo que despeja el futuro del sector.

El auge de la RA queda reflejado en el número creciente de periódicos que la utilizan; un incremento sin duda impulsado por la generalización del uso de los dispositivos móviles (Informe Deloitte, 2015). España es el segundo país con mayor tasa de penetración de smartphones, según dicho Informe. El $88 \%$ de los españoles posee un dispositivo smartphone, lo que coloca al país en el segundo puesto en tasa de penetración de estos dispositivos por detrás de Singapur con un $92 \%$ y por delante de la media europea del 78\% (Deloitte, 2015). Un análisis exhaustivo de la situación actual de la sociedad de la información en España, realizado anualmente por la Fundación Telefónica, indica en su informe de 2015 -referido a datos de 2014- que la digitalización de actividades es constante e imparable en el país, debido a que los ciudadanos se han acostumbrado a realizarlas de forma digital hasta el punto de prescindir en ocasiones de la forma tradicional; así, el $69 \%$ de los usuarios utiliza solo el formato digital para enviar un correo y el $63 \%$ para compartir fotos. Entre los que utilizan ambos formatos, el digital es el favorito con diferencia. Ante este avance de lo digital, el formato tradicional se mantiene inexpugnable solo en la lectura de libros, tanto en utilización como en valoración (Fundación Telefónica, 2015). A la vista de ello, podemos considerar que la población española es altamente receptiva ante el uso de tecnologías digitales para incorporarlas a la vida cotidiana.

En este sentido, las gafas de visualización lanzadas por dos multinacionales y una Start Up (Moverio de Epson, Space Glass de Meta y Google Glass) comienzan a marcar un antes y un después en el consumo de contenidos. Los autores de este trabajo interpretan esta proliferación en un contexto internacional de rentabilización de las inversiones en I+D+i, sorprendiendo a los usuarios con nuevas opciones de consumir información. La RA reúne rasgos que la hacen útil en ámbitos tan variados como la comunicación social, la cirugía, la psicología clínica y la docencia. Es fácil de utilizar y aporta complementariedad a contenidos impresos que no logran el impacto deseado por los emisores ni un efecto comunicativo satisfactorio en los destinatarios. Esta tecnología de visualización diversifica la narrativa periodística; añade datos, información y contenidos que dibujan ante la mirada de los usuarios escenarios informativos más completos, puesto que lo percibido a simple vista es aumentado (completado o complementado) con contenidos virtuales superpuestos que van desde simples datos a modelados diseñados en 3D. La idea matriz parte de que ningún escenario observado de forma directa ofrece el máximo de información concerniente al propio escenario. Si proyectamos esa idea a los periódicos impresos o al embalaje de productos, y si consideramos que los escenarios físicos son las páginas y los envases, identificaremos numerosos ejemplos de aplicación de RA, en los que la combinación de papel y RA causa en el usuario sensaciones variadas.

Lo cierto es que la RA puede llegar a ser una nueva forma de hacer periodismo que puede traer consigo nuevos modelos de negocio. Casero-Ripollés y Cullell March (2013) señalan que la crisis económica ha producido un gran daño a la industria periodística, llevando al cierre de numerosos diarios y al desempleo en la profesión a nivel internacional. Consideran que es momento de cambiar el modelo de negocio, fomentando el emprendimiento en el sector. El conocimiento de las tecnologías aplicadas al sector periodístico es clave para crear nuevas fórmulas empresariales basadas en el autoempleo digital y en la emprendeduría.

\section{FUNDAMENTOS METODOLÓGICOS DEL ESTUDIO}

Para trabajar la complejidad tecnológica y versatilidad comunicativa de la RA hemos estructurado el estudio en dos bloques:

1 Aplicación de la RA desde la perspectiva profesional del periodismo, planificando dos experiencias participativas en forma de taller, con 62 alumnos de comunicación social.

2. Aplicación de la RA desde la perspectiva educativa, introduciéndola en el proceso de enseñanza-aprendizaje de varias asignaturas.

En el primer bloque acometimos dos modalidades de trabajo: 
1.a) La revisión teórica del fundamento y versatilidad comunicativa de la RA.

1.b) La realización de dos experiencias con estudiantes, evaluadas mediante dos herramientas diseñadas ex profeso: una encuesta para recoger datos cuantitativos y un cuestionario (entrevista impresa). Fueron respondidas tras finalizar el taller, que constó de demostraciones interactivas dedicadas a las aplicaciones de RA en periodismo y en marketing.

Los resultados cuantitativos y cualitativos extraídos de la encuesta y el cuestionario fueron tratados estadísticamente, analizados, interpretados y sintetizados en las conclusiones.

En el segundo bloque nos centramos en el aprovechamiento de la RA para enseñar los procesos discursivos y la narración periodística no-lineal en medios impresos. Para ello utilizamos esta tecnología en los materiales docentes y en las prácticas de las asignaturas Comunicación Audiovisual: Televisión y Radio Informativa del Grado de Periodismo y Horizontes audiovisuales en la época de Internet del Máster Universitarios en Ciencias de la Comunicación, impartidas por la autora. Durante este estudio, la atención se dirigió a observar la reacción de los alumnos ante la presentación y uso de esta tecnología, y en reflexionar sobre el valor periodístico de la RA, analizando las posibilidades que proporciona al ámbito de la comunicación periodística impresa.

La experiencia se centró en los beneficios de visualizar, junto con el texto impreso, vídeos o animaciones asociadas a los hechos noticiosos; a la posibilidad de que una infografía adquiera vida mediante una animación o a que una gráfica se convierta en interactiva pudiendo realizar consultas pulsando con el dedo en los datos.

En el diseño de este estudio supuso un incentivo considerar que la exposición de hechos noticiosos, con su complejidad intrínseca, no quedara limitada a la linealidad de la página impresa; es decir, que se planteó la posibilidad de superar los límites impuestos por la plana de papel a la narrativa periodística impresa. La versatilidad de la RA rompe la limitación del soporte impreso, y descubre a los estudiantes otras posibilidades expresivas en la elaboración de contenidos periodísticos.

Otro gran potencial de la RA para la industria periodística es el derivado de la explosión creativa que supone en el ámbito de la publicidad, asociándola con videojuegos interactivos. La finalidad última fue introducirles en la innovación basada en las tecnologías de visualización, la convergencia y la digitalización.

\section{Objetivos de la investigación}

Este trabajo partió de las cuestiones siguientes, referidas a la narración y a la lectura periodística:

- Qué tipo de sensaciones causa en los lectores observar elementos virtuales emanados de una página de papel.

- Cuál es la percepción que tienen de la RA los futuros periodistas.

- En qué medida la RA ofrece alternativas para narrar historias trascendiendo las posibilidades del papel.

Para dar respuesta a estos interrogantes se plantearon cuatro objetivos:

O.1. Diseñar herramientas que permitan evaluar la usabilidad de la RA en medios impresos, desde la perspectiva del periodista y del lector.

O.2. Conocer las reacciones ante la tecnología de visualización RA como herramienta narrativa.

O.3. Cuantificar la usabilidad de la RA en periodismo impreso.

O.4. Analizar las expectativas de la RA para redactores y lectores.

En función de los resultados de usabilidad podremos plantear mejoras en la aplicación y usos comunicativos de esta tecnología en medios impresos. En lo referente a las expectativas, pueden ser tenidas en cuenta por los agentes implicados en la edición de medios impresos para innovar y revalorizar su consumo.

Partimos de las conjeturas siguientes:

H1. Los contenidos de RA asociados a la lectura de prensa producen en el lector cercanía a la noticia y proporciona mayor credibilidad a la información.

H2. La tecnología de RA aplicada en el ámbito periodístico es una alternativa de renovación y actualización del profesional de la información.

H3. El uso de RA contribuye a acercar la prensa a las generaciones jóvenes.

\section{Participantes y materiales}

Para conocer cuál es la percepción de esta tecnología y sus efectos comunicativos, hemos limitado los cuestionarios diseñados a dos de los agentes del proceso: periodistas y lectores de prensa. Dado que este estudio se centra en la utilización de la RA en la elaboración de contenidos periodísticos y su consumo, 
los ítems que han debido valorar los encuestados se centran en redactores y receptores.

Se diseñaron dos instrumentos de medición. El primero fue una encuesta para conocer la percepción que tiene el receptor de la información y el periodista de la incorporación de contenidos multimedia, mediante la tecnología de RA, a lo impreso en los periódicos. El segundo fue un cuestionario destinado a medir la usabilidad de esta tecnología en los medios impresos.

El universo de esta investigación lo integran estudiantes de dos titulaciones de Comunicación Social. En la selección de los dos grupos de encuestados se incluyeron a alumnos de primer curso del Grado en Periodismo y a otros del Máster en Ciencias de la Comunicación de la Universidad de La Laguna (ULL). Esta selección abarca a estudiantes de nuevo ingreso y a otros de posgrado con experiencia en medios de comunicación. De los 62 participantes, 57 eran de Grado y el resto de Máster, todos ellos contestaron la encuesta bajo ambos roles, de lector y de periodista, ya que la encuesta está estructurada en dos bloques de preguntas, unas para contestar bajo la perspectiva de lector de prensa y otro bloque para contestar bajo la perspectiva profesional. Las edades estaban comprendidas entre los 18 y los 38 años. No se hizo distinción por sexo por ser irrelevante en esta investigación. Las encuestas se realizaron en mayo y noviembre de 2012.

Se utilizó la aplicación informática de RA Aurasma descargable desde Play Store de Google o Apple Store, y compatible con los dos tipos de dispositivos móviles utilizados en el estudio: smartphones y tabletas con los sistemas operativos Android e iOS. Trabajos recientes recogen ejemplos de medios de referencia estadounidenses (New York Times, Wall Street Journal) que utilizan Aurasma, considerada la aplicación de RA más potente para integrar el diario impreso con los dispositivos móviles (Pavlik, 2011).

La realidad física en esta experiencia la integró páginas impresas de diarios. Aurasma facilita usar como patrones o marcas de reconocimiento cualquier tipo de imagen; aquí han sido fotografías y fragmentos de texto de las páginas de los diarios que hemos fotografiado para convertirlos en imágenes-marcas; a esas marcas vinculamos, mediante Aurasma, contenidos audiovisuales, interactivos y 3D.

\section{Diseño de la encuesta de percepción de la RA aplica- da en medios impresos}

La encuesta diseñada ad hoc constó de 27 ítems organizados en bloques, según se trataran de cues- tiones valoradas desde la perspectiva del lector de periódicos o desde la de profesionales de la información (tabla III).

Bajo la perspectiva de lector, la investigación trata de buscar indicadores de los cambios de percepción que produce la lectura de noticias (si produce cercanía/empatía, convicción y credibilidad, curiosidad por los detalles de la información, percepción de realidad). Desde el punto de vista técnico se busca saber si se interactúa con la información para ampliar información y saber más sobre la noticia o el producto publicitado, si le divierte ciertas acciones destinadas al entretenimiento y asociadas a las noticias o a la publicidad.

En el bloque destinado a conocer la percepción del profesional de los medios de comunicación, se buscan indicadores de si la tecnología es adecuada para complementar la prensa, si puede ser una evolución del medio impreso y de sus profesionales, si favorece la evolución profesional fomentando la imaginación, la innovación expresiva y narrativa, si optimiza la narración y estimula la creatividad.

Un tercer bloque formado por cinco preguntas iba enfocado a conocer la opinión del encuestado sobre si considera o no que la RA es una tecnología fácilmente aceptada por la sociedad.

El segundo instrumento utilizado fue el cuestionario destinado analizar la usabilidad (eficiencia, eficacia y satisfacción) de la RA aplicada en periodismo impreso (tabla IV). Fue diseñado para ser evaluada por el lector como destinatario que utilizará la tecnología. Constó de 26 ítems categorizados en tres bloques que evalúan cada una de las componentes de usabilidad. En cuanto a la eficiencia, las cuestiones hacen referencia a aspectos técnicos referidos a si los contenidos (audiovisuales, animaciones o elementos interactivos) se ven correctamente o si presentan errores que imposibilitan o dificultan comprenderlos o reproducirlos. Las cuestiones de eficacia incidían en si los contenidos sirven o no para el propósito que se han creado: complementar la información de forma adecuada y accesible. El tercer bloque, referente a la satisfacción, permitió conocer la percepción del usuario sobre el uso de RA aplicada a la prensa.

\section{DESARROLLO DE LA EXPERIENCIA}

Una vez seleccionados los dos grupos de encuestados, la planificación del estudio exigió que los estudiantes adoptan la perspectiva del periodista y la de lector de prensa, en función del cuestionario respondido. 
Los alumnos grabaron en vídeo contenidos relacionados con una noticia (contenidos aumentados) que había sido cubierta por los diarios locales (noticia impresa). Se editaron los contenidos aumentados en archivos digitales que los autores almacenaron en el servidor de Aurasma:

- Una vídeo-noticia de 2 minutos de duración enlazada a la fotografía de la plana del diario (http://t.ull.es/53j).

- Un vídeo de 2 minutos y medio con hipervínculos interactivos de temática relacionada con la noticia, grabado en un museo provincial (http://t.ull.es/53k).

- Un modelado 3D interactivo (infografía) de elaboración propia.

- Un tráiler de 20 segundos de duración de una película relacionada con la temática de la noticia, tomado del servidor de Aurasma.

Una vez vinculados estos cuatro elementos digitales a las páginas del periódico, con Aurasma abierto en el dispositivo, al enfocar cada página con el dispositivo móvil el usuario observa cómo de ella surgen los contenidos complementarios de lo que ha leído.

La experiencia-taller, de dos horas de duración, comenzó indicando a los participantes que iban a leer de forma especial noticias en periódicos, y se les solicitó que instalaran en sus dispositivos la aplicación Aurasma. También se les indicó que las noticias que tuvieran el logotipo AR podrían utilizar dicha aplicación para complementar la información que estaban leyendo. Sin adelantarles nada más, se proporcionó a los participantes copias del diario para que leyeran las noticias y luego dirigieran la cámara del dispositivo hacia las páginas del periódico con el logotipo identificativo; de esa forma pasaron a visualizar los contenidos aumentados. Los autores prestaron atención especial a las reacciones de los participantes durante esta fase del estudio. Al término de la experiencia-taller se entregó a los participantes la encuesta y el cuestionario, que cumplimentaron de forma anónima; ningún encuestado planteó dudas sobre la comprensión de los enunciados.

\section{Los contenidos aumentados}

Los contenidos aumentados utilizados en este trabajo fueron audiovisuales, multimedia, interactivos y tridimensionales; como se ha dicho, en unos casos los elaboraron estudiantes del Master en Ciencias de la Comunicación y, en otros, se seleccionaron del servi- dor de Aurasma por estar relacionados con las noticias impresas. Para acceder al contenido digital aumentado, los usuarios necesitaron un dispositivo con cámara y conexión a Internet; en este caso trabajamos con smartphones y tabletas. En su pantalla se visualizaban el entorno real capturado por la cámara, es decir, las páginas de periódicos, al que se iban superponiendo los contenidos digitales aumentados, solo visibles en la pantalla del dispositivo (figura 4). Los elementos activadores o marcas de RA fueron fotografías y fragmentos de texto convertidos en imágenes, tomados de las páginas de los periódicos; a estas fotografíasmarcas impresas vinculamos los contenidos aumentados, siguiendo las instrucciones de Aurasma.

Figura 4. Alumno leyendo un periódico aumentado con la tableta

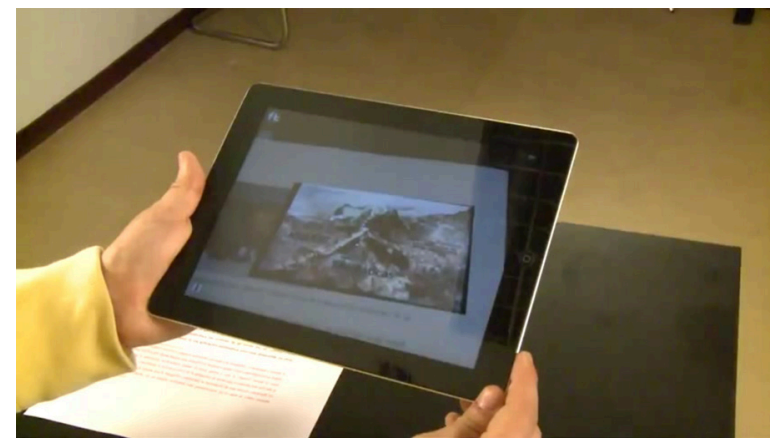

\section{Usabilidad}

J. Preece y colaboradores (2002) definen la usabilidad como la facilidad de uso, ya sea de una página web, de una aplicación informática o de cualquier otro sistema con el que interactúe el usuario. Estos autores indican que está relacionada con el desarrollo de interacciones en productos -sean sistemas, tecnologías, herramientas, aplicaciones o dispositivos- fáciles de aprender, efectivos y de utilización agradable desde la perspectiva del usuario. En el ámbito de las tecnologías y de la computación, la usabilidad se entiende como la capacidad de una aplicación o producto para dejarse usar con facilidad y de forma intuitiva, facilitando la experiencia del usuario en lugar de entorpecerla (Hornbæk, 2006).

N. Bevan (1999) indica que es difícil establecer formas de probar, medir, evaluar y comparar resultados cuantificables de la experiencia del usuario; por ello es necesario definir métodos, métricas, procesos y herramientas de medición para conocer la usabilidad de una aplicación tecnológica o de un producto. 
La norma ISO/IEC 9241-11 cita la usabilidad como "la medida en que los usuarios de los productos son capaces de trabajar de manera eficaz, eficiente y con satisfacción". Esta definición ISO está centrada en el concepto de calidad en el uso (Quality in Use), y alude a cómo el usuario realiza tareas concretas en escenarios específicos con efectividad (Satisfaction questinnaries, 2000). La norma indica cómo se puede medir las tareas y la satisfacción de los usuarios al interactuar con un sistema.

Bevan (1999, 2006), en consonancia con la norma ISO, define las componentes de usabilidad de la forma siguiente:

- Eficacia: exactitud e integridad. Las tareas que se llevan a cabo en el uso de un producto están libres de error. Un producto es eficaz según el grado de exactitud con que se realizan las tareas y cumple los objetivos para los que está diseñado.

- Eficiencia: los recursos asignados. La rapidez con que un usuario efectúa un trabajo es fundamental para la productividad. Un producto es eficiente cuanto más rápido realiza las tareas para las que ha sido diseñado.

- Satisfacción: cumplir con las expectativas. La satisfacción es un factor de éxito en cualquier producto. Es fundamental para mantener la motivación del usuario. En ISO 9241 se define como "la libertad del usuario para mostrar su conformidad/disconformidad y sus actitudes hacia la utilización de un producto".

Bevan sostiene que estas componentes se pueden medir mediante cuestionarios específicos, e indica que la medida de la eficacia resulta del valor medio de las respuestas de los participantes, utilizando una escala numérica graduada; y respecto a la eficiencia y la satisfacción, serán un valor en una escala cualitativa que permita una reflexión-conclusión, en función de cómo se formulen las preguntas.

La medida de la satisfacción (Likability) es más fiable cuando se utilizan encuestas que han sido validadas psicométricamente. Sin embargo, es difícil obtener encuestas de este tipo que se puedan adaptar a experiencias particulares. En este estudio se han redactado ítems específicos en forma de enunciados afirmativos, teniendo en cuenta la experiencia de $\mathrm{K}$. Hornbæk (2006). El cuestionario diseñado constituye una herramienta que permite la recolección de datos necesarios para medir la usabilidad de la RA en los medios impresos. Ambas herramientas, encuesta y cuestionario, miden conjuntamente aspectos referentes al uso, funcionamiento, viabilidad, creatividad, usabilidad (eficacia, eficiencia y satisfacción) e, incluso, sensaciones en la recepción de la información.

Los ítems fueron redactados en forma asertiva para garantizar su uniformidad y no influir en los resultados. Tal formulación permite expresar opinión, experiencias, intención, acción, situaciones y procesos, información y motivos. Las opciones de respuestas fueron cerradas, categorizadas, espontáneas y escalonadas en una escala de Likert de cinco puntos de valoración de 1 (inferior) a 5 (superior).

\section{RESULTADOS Y ANÁLISIS}

La tabla III muestra los valores medios y desviaciones típicas de los ítems de la encuesta sobre las apreciaciones de los usuarios como lectores y como profesionales de medios informativos. Todas las preguntas fueron contestadas, desde ambas perspectivas, con valores muy altos en cuanto a la percepción. Sobre una valoración máxima de 5 puntos, la mayoría de los ítems tienen valores iguales o superiores a 4 . Los resultados referidos a la percepción de los lectores en el uso de RA para complementar el contenido impreso indican que les produce una mayor cercanía a la noticia; y, en función del tipo de acontecimiento noticioso, consideran que fomenta la curiosidad por la información, sienten inmersión en la noticia al visualizarla inserta en un contexto recreado audiovisualmente, perciben que les transmite mayor credibilidad y convicción sobre lo leído y consideran que esta tecnología puede permitirles, en función de la noticia, divertimiento e interactuar con la información, según el caso. Son resultados coincidentes con el estudio de J. Pavlik, quien también atribuye a la RA la capacidad de involucrar a la ciudadanía en el acontecer, mediante otra forma de contar las historias periodísticas (Pavlik, 2013a, 2013b).

Desde el punto de vista del periodista, los encuestados consideran que la RA supone una renovación y actualización del profesional al que se le exige la adquisición de nuevas competencias profesionales. Fomenta la innovación expresiva y narrativa, lo que les facilita la exposición así como la optimización de la narración, al permitirles incorporar contenido visual y audio, cuyas sensaciones es difícil de transmitir solo con la escritura. La encuesta refleja que la RA estimula la creatividad periodística y fomenta la imaginación de los editores de noticias.

Desde la perspectiva del periodista, los participantes consideran que esta tecnología visual rejuvenece la prensa y es una novedad para la sociedad de la información, 
ya que la califican como una tecnología agradable de usar, original y amena por el interés y curiosidad que despierta.

En lo relativo a la complicación presentada por la creación de los contenidos aumentados, la valoración no es tan alta como el resto de aspectos; no obstante, es valo- rada con 3,56 puntos de media sobre 5 . Consideramos que esta barrera se debe al hecho de tener que dominar el diseño de infografías, la edición de vídeo, el modelado 3D o colaborar con otros profesionales que elaboren estos materiales para asociarlos a las páginas impresas.

Tabla III. Medición de apreciaciones del receptor de la información y del profesional de los medios de comunicación

\begin{tabular}{|c|c|c|c|c|}
\hline $\begin{array}{l}\text { En la producción y edición de contenidos } \\
\text { (profesional de medios de comunicación) }\end{array}$ & & $\begin{array}{l}\text { Valor } \\
\text { medio }\end{array}$ & $\begin{array}{l}\text { Desviación } \\
\text { Estándar } \\
\text { (SD) }\end{array}$ & $\begin{array}{c}\text { Error } \\
\text { estándar de } \\
\text { la media }\end{array}$ \\
\hline 1. El sistema de Realidad Aumentada supone aportes nuevos & Q1 & 4,41 & 0,72 & 0,09 \\
\hline \multicolumn{5}{|c|}{ Partiendo del hecho que esta tecnología aporta nuevas posibilidades y experiencias narrativas, indique el grado de acuerdo: } \\
\hline \multicolumn{5}{|l|}{ PARA EL LECTOR } \\
\hline 2. Produce cercanía a la noticia & Q2 & 4,00 & 0,85 & 0,11 \\
\hline 3. Provoca convicción en el lector & Q3 & 3,92 & 0,79 & 0,10 \\
\hline 4. Fomenta la creatividad en la confección de la noticia & Q4 & 4,46 & 0,82 & 0,11 \\
\hline 5. Transmite credibilidad en el lector & Q5 & 3,86 & 0,92 & 0,12 \\
\hline 6. Produce curiosidad en el lector & Q6 & 4,49 & 0,86 & 0,11 \\
\hline 7. Permite idear productos periodísticos para divertir al lector & Q7 & 4,58 & 0,67 & 0,09 \\
\hline 8. Permite la inmersión del lector en la noticia y percibir la realidad & Q8 & 4,36 & 0,74 & 0,10 \\
\hline 9. La noticia impresa con RA proporciona interactividad & Q9 & 4,20 & 0,98 & 0,13 \\
\hline \multicolumn{5}{|c|}{ PARA EL PROFESIONAL DE LOS MEDIOS DE COMUNICACIÓN } \\
\hline 10. La RA rejuvenece los medios informativos en papel & Q10 & 4,36 & 0,78 & 0,10 \\
\hline 11. La tecnología de RA implica una evolución profesional & Q11 & 4,27 & 0,78 & 0,10 \\
\hline $\begin{array}{l}\text { 12. RA permite exponer contenidos periodísticos que son percibidos con } \\
\text { fiabilidad por el lector }\end{array}$ & Q12 & 3,92 & 0,77 & 0,10 \\
\hline 13. La RA fomenta la imaginación del editor de la noticia & Q13 & 4,39 & 0,72 & 0,09 \\
\hline 14. La RA fomenta la innovación expresiva & Q14 & 4,25 & 0,84 & 0,11 \\
\hline 15. La RA fomenta la innovación narrativa & Q15 & 4,03 & 0,87 & 0,11 \\
\hline 16. La RA optimiza la narración & Q16 & 3,92 & 0,88 & 0,11 \\
\hline 17. La RA estimula la creatividad periodística & Q17 & 4,36 & 0,69 & 0,09 \\
\hline $\begin{array}{l}\text { 18. La RA permite soluciones visuales que con la escritura difícilmente se } \\
\text { podrían lograr }\end{array}$ & Q18 & 4,46 & 0,77 & 0,10 \\
\hline 19. La RA favorece la explicación narrativa & Q19 & 4,08 & 0,84 & 0,11 \\
\hline 20. La RA exige competencias profesionales nuevas & Q20 & 4,34 & 0,80 & 0,10 \\
\hline 21. La RA supone una renovación profesional & Q21 & 4,44 & 0,77 & 0,10 \\
\hline \multicolumn{5}{|l|}{ OTRAS OPINIONES: } \\
\hline $\begin{array}{l}\text { 22. Considero que la RA es una novedad para la sociedad de la } \\
\text { información }\end{array}$ & Q22 & 4,64 & 0,55 & 0,07 \\
\hline 23. Desde el punto de vista estético, es una tecnología agradable & Q23 & 4,00 & 0,82 & 0,11 \\
\hline 24. La tecnología de RA es interesante & Q24 & 4,47 & 0,82 & 0,11 \\
\hline 25. Considero que la RA es original & Q25 & 4,46 & 0,75 & 0,10 \\
\hline 26. La creación de aplicaciones de RA es complicada & Q26 & 3,56 & 1,22 & 0,16 \\
\hline
\end{tabular}


La figura 5 muestra los resultados de la tabla III anterior. Las valoraciones de los participantes ponen de manifiesto una percepción muy positiva de la aplicación de la RA en el periodismo impreso.

La tabla IV contiene los datos referentes al estudio de usabilidad de la tecnología de RA aplicada a medios impresos.

El cuestionario mide la usabilidad de la visualización por el lector de contenidos aumentados a partir de medios impresos, utilizando dispositivos móviles (tabla IV). La figura 6 muestra que los valores alcanzados en las tres componentes analizadas (eficacia, eficiencia y satisfacción) están en torno a 4 puntos de valoración sobre 5 en una escala de Likert. En referencia a la eficiencia, las cuestiones evaluadas aluden a la rapidez y precisión con que se recibe la información; evalúan la calidad con la que se ven los elementos vir-

Figura 5. Apreciaciones de los lectores y profesionales

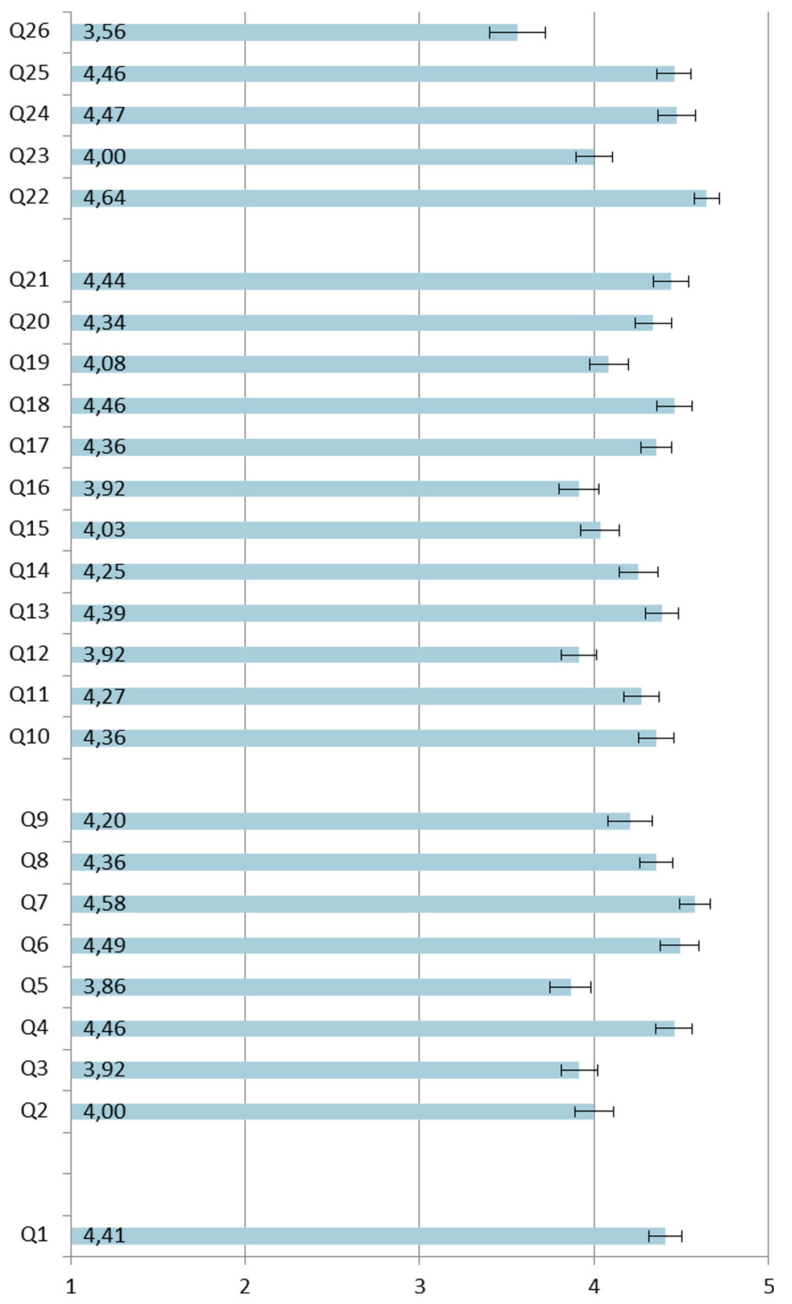

tuales (definición de la imagen, tiempo de ejecución y precisión), aportando un valor de 4,12 sobre 5 .

La eficacia de esta tecnología aplicada a periódicos impresos se evalúa con cuestiones referidas a los objetivos que debe cumplir, obteniéndose un valor medio de 3,98.

El lector muestra una satisfacción positiva por el uso de esta herramienta. Solo se han formulado 4 preguntas con el objeto de medir esta componente de forma restrictiva, ya que con pocas preguntas es poco probable ocultar la falta de satisfacción. El valor obtenido para la componente de satisfacción es 3,83 sobre 5, lo que significa un alto grado de satisfacción en el uso de esta tecnología, asociado a una valoración muy alta de la usabilidad.

Con objeto de comprobar si hay diferencias significativas en las apreciaciones de los dos grupos de alumnos (Grado y Máster), realizamos comparaciones entre los valores medios obtenidos para cada una de las secciones de ambos cuestionarios. Aplicamos el estadístico t-Student para dos muestras independientes de diferentes tamaños que siguen una distribución normal, considerando en todos los casos como hipótesis nula (Ho) el hecho que los valores medios de cada una de las secciones de percepción y de usabilidad son diferentes. En otras palabras, partimos del hecho de que Ho indica que los alumnos de grado y máster tienen distinta apreciación sobre la aplicación de RA en el periodismo. Los resultados de comparación de los valores medios de cada sección por grupo de estudiantes se muestran en la tabla V. Los valores obtenidos indican que no hay diferencia estadística significativa entre ambos grupos en ninguna de las secciones. En todos los casos los p-valores son superiores a 0,05 , por tanto afirmamos que ambos grupos de alumnos tienen, desde el punto de vista estadístico, la misma percepción en el estudio realizado.

Este resultado indica que el procesamiento de los resultados correspondientes a los alumnos de Grado y a los de Máster no reveló diferencias en la percepción de la aplicación de la RA a medios impresos, ya que ni unos ni otros tenían conocimiento de esta tecnología.

\section{DISCUSIÓN}

La aun incipiente bibliografía y recursos en Internet dedicados a la RA en periodismo indican que los editores de los medios coinciden en que esta tecnología les permite renovar el soporte papel, incrementando el interés de las audiencias. Los sectores más jóvenes de la población y los anunciantes son dos públicos diana para ganar nuevos lectores y clientes familiarizados con las TIC. La RA permite diversificar la oferta publicitaria 
Tabla IV. Medidas de las componentes de la usabilidad

\begin{tabular}{|c|c|c|c|}
\hline A. Eficiencia de la aplicación de tecnología (según el receptor) & & Media & $\begin{array}{l}\text { Desviación } \\
\text { estándar (SD) }\end{array}$ \\
\hline A1. La visualización del vídeo es cómoda, no presenta vibraciones, saltos, retardos & A1 & 3,79 & 0,89 \\
\hline A2. El vídeo no tiene problemas de definición (pixelado, borroso, oscuro) & $\mathrm{A} 2$ & 3,81 & 0,94 \\
\hline A3. El vídeo complementa la información impresa & A3 & 4,48 & 0,65 \\
\hline A4. Lo que despliega la aplicación es visualmente atractivo & A4 & 4,41 & 0,84 \\
\hline $\begin{array}{l}\text { A5. El vídeo aparece sobre la plana en el lugar adecuado de la noticia, es decir, no hay } \\
\text { dudas sobre a qué noticia impresa complementa }\end{array}$ & A5 & 4,31 & 0,80 \\
\hline A6. La RA facilita al lector transportarse al lugar del hecho noticioso & A6 & 4,23 & 0,72 \\
\hline Valoración Eficiencia & & 4,12 & 0,86 \\
\hline B. Eficacia de la aplicación de RA en la noticia (según el receptor) & & Media & $\begin{array}{l}\text { Desviación } \\
\text { estándar (SD) }\end{array}$ \\
\hline $\begin{array}{l}\text { B1. Es fácil utilizar la RA con mi dispositivo, sobre un periódico impreso para disfrutar de } \\
\text { contenidos digitales }\end{array}$ & B1 & 3,70 & 1,19 \\
\hline B2. La información aumentada me ha proporcionado más información que la leída & B2 & 4,08 & 0,75 \\
\hline B3. La información aumentada me ha dado sensación de acercarme más al tema de la noticia & B3 & 4,15 & 0,83 \\
\hline B4. La información aumentada con el vídeo me parece acertada y creíble (fiabilidad) & B4 & 4,08 & 0,80 \\
\hline B5. La noticia aumentada favorece la comprensión del texto impreso & B5 & 4,26 & 0,73 \\
\hline B6. La información aumentada permite la interactividad con el usuario & B6 & 4,06 & 0,92 \\
\hline B7. La información aumentada favorece la imaginación del usuario & B7 & 3,94 & 0,99 \\
\hline Valor medio eficacia & & 3,98 & 0,91 \\
\hline C. Satisfacción del receptor & & Media & $\begin{array}{l}\text { Desviación } \\
\text { estándar (SD) }\end{array}$ \\
\hline C1. Es un inconveniente tener que depender del móvil, tableta o PC & $\mathrm{C} 1$ & 3,34 & 1,39 \\
\hline C2. El uso de RA estimula consumir periódicos impresos & $\mathrm{C} 2$ & 3,48 & 1,21 \\
\hline C3. Se perciben sensaciones nuevas que solo con el texto impreso no se experimentan & $\mathrm{C} 3$ & 4,26 & 0,92 \\
\hline C4. Prefiero la noticia aumentada y no solo el texto impreso & $\mathrm{C} 4$ & 4,34 & 0,75 \\
\hline Valor medio satisfacción & & 3,83 & 1,17 \\
\hline
\end{tabular}

Figura 6. Medición de la eficacia, de la eficiencia, de la satisfacción y de la opinión sobre la RA aplicada al periodismo

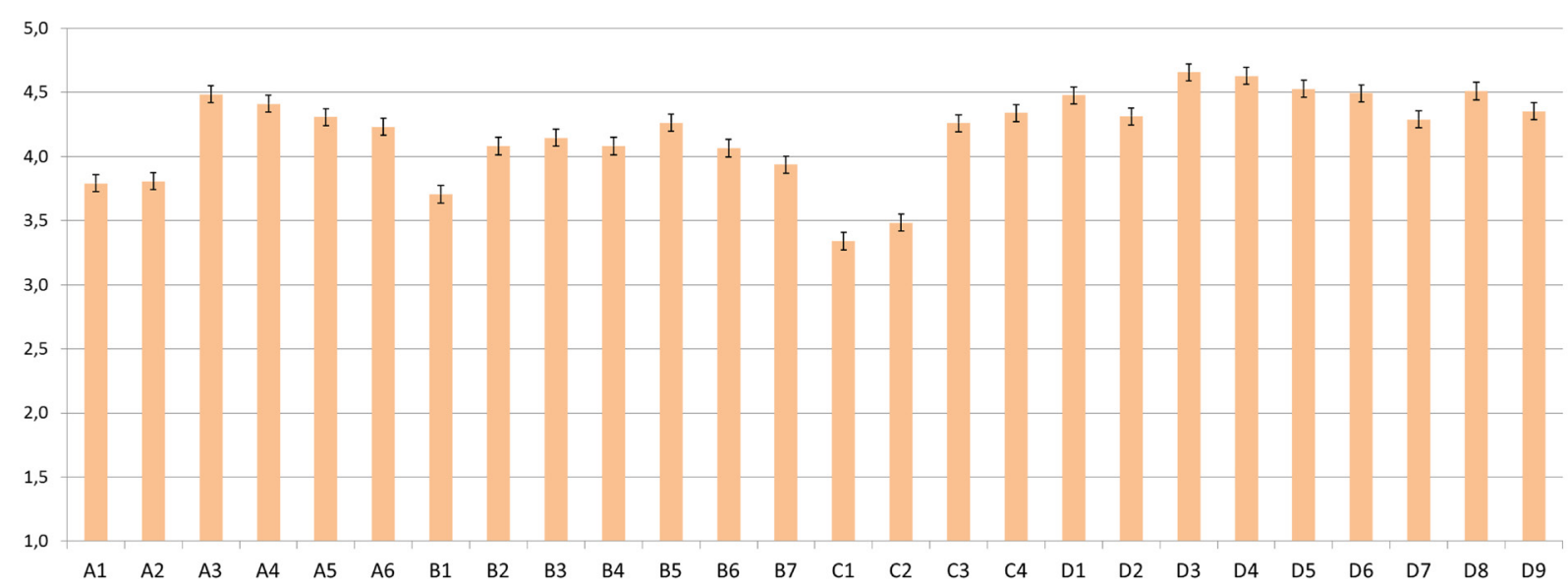


Tabla V. Resultados de análisis de comparación mediante estadístico t-student

\begin{tabular}{|c|c|c|c|c|}
\hline \multicolumn{2}{|c|}{$\begin{array}{c}\text { Cuestionario Q1 } \\
\text { (percepción de la tecnología) }\end{array}$} & $\begin{array}{c}\text { Cuestionario Q2 } \\
\text { (Usabilidad) }\end{array}$ \\
\hline Rol Lector & $\begin{array}{c}\text { Rol Profesional } \\
\text { comunicación }\end{array}$ & A. Eficiencia & B. Eficacia & C. Satisfacción \\
\hline $\begin{array}{c}\mathrm{p} \text {-valor }=0,791 \\
\mathrm{t}=-1,163\end{array}$ & $\begin{array}{c}\mathrm{p} \text {-valor }=0,563 \\
\mathrm{t}=1,062\end{array}$ & $\begin{array}{c}\mathrm{p} \text {-valor }=0,551 \\
\mathrm{t}=2,705\end{array}$ & $\begin{array}{c}\mathrm{p} \text {-valor }=0,277 \\
\mathrm{t}=1,238\end{array}$ & $\begin{array}{c}\mathrm{p} \text {-valor }=0,382 \\
\mathrm{t}=0,053\end{array}$ \\
\hline
\end{tabular}

para impactar más y mejor. A este respecto destaca que los expertos en la edición de prensa y en publicidad insistan en que el foco de interés para incrementar el negocio está, precisamente, en la publicidad impresa.

Considerando los cuatro objetivos marcados, podemos concluir que la encuesta realizada, basada en demostraciones reales participativas, muestra dos facetas destacables: una es la carga de sorpresa y asombro por la asociación inmediata entre el papel y lo audiovisual, y otra es la reflexión sobre las posibilidades profesionales y de consumo de la RA. La satisfacción, la eficacia y la eficiencia de la aplicación de RA obtuvieron una valoración positiva en esta experiencia. Las dos herramientas de evaluación diseñadas -encuesta y cuestionario- fueron eficaces en la investigación desarrollada, cumpliéndose el objetivo 1.

La dificultad mayor para el usuario es la inexistencia de una aplicación universal para todos los dispositivos y sistemas operativos. El hecho de que cada periódico utilice una aplicación distinta condiciona al usuario final, que debe instalarla en su dispositivo. A pesar de ello, los resultados de la encuesta y del cuestionario indican que esta tecnología es bien recibida por ser llamativa, muy visual y sorprendente. Por tanto damos por cumplidos los objetivos 2 y 4.

La RA afecta a los profesionales que deseen aplicarla. Su introducción en la redacción del medio requiere cierta inversión para adquirir los dispositivos necesarios y formar al personal involucrado, aunque otra opción es externalizar el servicio, encargando la elaboración de los contenidos aumentados a empresas especializadas. La coordinación entre redactores, diseñadores gráficos y realizadores audiovisuales es clave para idear contenidos aumentados adecuados a sus necesidades, y bien articulados con los contenidos impresos. A pesar de requerirse una formación en esta tecnología, los resultados cuantitativos indican una alta valoración de la usabilidad. Su facilidad de uso permite cumplir las expectativas que se proponga la Redacción de cualquier periódico impreso, con lo que se cumple el objetivo 3 y se reafirma el 4.

\section{CONCLUSIONES}

Estamos ante una tecnología convergente, ya que permite unir el papel, el vídeo, el audio, la imagen 2D y 3D, la información inteligente, la ampliación, combinación, complementariedad y la verificación de datos y declaraciones, así como incorporar infografías interactivas, entre otras formas expresivas. Para unos autores cabe hablar de un periodismo de inmersión digital (Domínguez Martín, 2013) y, para otros, de periodismo contextualizado (en sentido geográfico) ( $\mathrm{Pa}$ vlik, 2001, 2011). En ambos casos, es un periodismo impreso apoyado en la RA destinado a introducir al lector-ciudadano en el escenario de la noticia con el objeto de fomentar su complicidad y coparticipación en los asuntos de interés público.

La versatilidad de la RA radica en que los contenidos aumentados no dependen de la temática, formatos ni géneros. Es posible aumentar noticias, reportajes, museos, páginas de papel, sitios arqueológicos, fachadas de edificios o cualquier imagen impresa sobre cualquier superficie. La cobertura de eventos in situ constituye otro tipo de uso rentable en marketing.

Los resultados indican que los lectores más jóvenes de periódicos y los futuros profesionales de la comunicación ven en este tipo de tecnología una nueva forma de estar informados y de hacer periodismo. La población española es la segunda a nivel mundial con más dispositivos móviles y la que más rápido se ha acostumbrado a realizar actividades digitales. Actividades que se hacían de forma tradicional ahora se han digitalizado en un alto porcentaje. Este hecho, junto con las percepciones que muestran los encuestados en este trabajo, hace pensar que la lectura del periódico con un dispositivo móvil para aumentar la información impresa puede llegar a ser una nueva actividad digital usual en la sociedad.

Tal como afirman Casero-Ripollés y Cullell-March (2013), la sociedad siempre necesitará de periodistas y los cambios en la industria periodística consecuencia de la crisis económica, así como los nuevos formatos y modelos de negocio, deben orientar las funciones de 
los profesionales de la comunicación para crear nuevas fórmulas empresariales que canalicen, ejecuten y presten los servicios que la profesión ofrece a la sociedad. Estos autores son conscientes de la necesidad de potenciar el emprendimiento en los periodistas, a los que se les abren oportunidades de poner en práctica iniciativas de autoempleo gracias a las tecnologías digitales.

Casero y Cullell inciden en la necesidad de elaborar propuestas formativas universitarias que fomenten la adquisición de competencias y mecanismos para promocionar el espíritu emprendedor como opción profesional entre los futuros periodistas. En este sentido, los futuros profesionales que han participado en el estudio ponen de manifiesto que esta tecnología aplica$\mathrm{da}$ al periodismo supone una oportunidad para crear un nuevo yacimiento de empleo. Y, para la industria periodística, impulsa un importante modelo de negocio basado en la publicidad. Las percepciones de los futuros profesionales de los medios de comunicación indican que la RA implicaría una evolución profesional al renovar los recursos expresivos y narrativos; por ello se precisarían habilidades creativas y un conjunto de nuevas competencias profesionales.

A la vista de los resultados obtenidos en el análisis realizado podemos concluir reafirmando las hipótesis propuestas. Los contenidos de RA asociados a las noticias impresas producen en el lector cercanía a la noticia y aumenta la credibilidad de la información. Este nuevo modelo de leer la prensa supone una renovación y actualización del profesional de la información que modernizaría la prensa.

\section{NOTAS}

1. http://www.gartner.com/technology/ research/methodologies/hype-cycle.jsp

2. http://goo.gl/oy1oYZ

3. http://goo.gl/XrLfTs
4. https://www.youtube.com/ watch?v=0Gc1zlgB0ql

5. http://vozpopuli.com/economia-yfinanzas/35456-los-periodicos-impre- sos-han-perdido-un-millon-de-lectores-en-los-ultimos-diez-anos

\section{BIBLIOGRAFÍA}

Bevan, N. (1999). Quality in Use: Meeting User Needs for Quality. Journal of System and Software, 49, 1, pp. 8996. http://dx.doi.org/10.1016/S01641212(99)00070-9

Bevan, N. (2006). Practical Issues in Usability Measurement. Interactions, 13, 6, pp. 42-43. http://dx.doi. org/10.1145/1167948.1167976

Bull, A. (2013). Brand Journalism. Londres: Routledge.

Casero-Ripollés, A. y Cullell-March, C. (2013). Periodismo emprendedor. Estrategias para incentivar el autoempleo periodístico como modelo de negocio. Estudios sobre el Mensaje Periodístico, 19, pp. 681-690.

Díaz Nosty, B. (2011). La crisis en la industria de la prensa. Vida más allá del papel... Telos. Cuadernos de Comunicación e Innovación, 86, pp. 52-65.

Domínguez Martín, E. M. (2013). Periodismo inmersivo: Fundamentos para una forma periodística basada en la interfaz y la acción [Tesis doctoral inédita]. Universitat Ramon Llull: Barcelona.

Furht, B. (ed.) (2011). Handbook of augmented reality. Springer.

Hornbæk, K. (2006). Current Practice in Measuring Usability: Challenges to Usability Studies and Research. International Journal of Human-Computer Studies, 64, 2, pp. 79-102. http://dx.doi. org/10.1016/j.ijhcs.2005.06.002

Lapointe, P. (2002). Utopie.net: la réalité Internet après le rêve. Québec: Éditions MultiMondes.

Meneses Fernández, M. D., y Martín Gu tiérrez, J. (2013). Realidad aumentada e innovación tecnológica en prensa. La experiencia de ver y escuchar un periódico impreso. Estudios sobre el Mensaje Periodístico, 19, 1, pp. 207-221. http:// dx.doi.org/10.5209/rev ESMP.2013. v19.n1.42517
Pavlik, J. V. (2001). Journalism and New Media. New York: Columbia University Press.

Pavlik, J. V. (2011). Digital technology and Journalism: implications for Democracy. Brazilian Journalism Research, 7, 2, pp. 95-116.

Pavlik, J. V. (2013a). Trends in New Media Research: A Critical Review of Recent Scholarship. Sociology Compass, 7, 1, pp. 1-12. http://dx.doi.org/10.1111/ soc4.12004

Pavlik, J. V. (2013b). The Emergence of Augmented Reality (AR) as a Storytelling Medium in Journalism. Journalism \& Communication Monographs, 15, 1, pp. 4-59. http://dx.doi. org/10.1177/1522637912470819

Preece, J., Rogers, Y. and Sharp, H. (2002). Interaction Design: Beyond HumanComputer Interaction. New York: John Wiley \& Sons. 


\section{Recursos electrónicos}

AEDE (Asociación de Editores de Diarios Españoles) (2008-2013). Libro Blanco de la Prensa Diaria. Estudios sobre los medios de prensa escrita desde las ópticas empresariales, tecnológicas, legales, éticas y de contenidos. [En línea]. Disponible en http://www.aede.es/hitos/ libro-blanco/

AEDE (Asociación de Editores de Diarios Es pañoles) (2013). Observatorio mensual de la prensa diaria, Madrid.

AEDE (Asociación de Editores de Diarios Españoles) (2015). Libro Blanco de la Prensa Diaria. Estudios sobre los medios de prensa escrita desde las ópticas empresariales, tecnológicas, legales, éticas y de contenidos. [En línea]. Disponible

\section{Otros recursos:}

http://challenges.talentegg.ca/how-canmetro-news-canada-use-augmentedreality-to-engage-its-audience-

http://www.j-source.ca/article/augmented-reality-latest-fad-newspapers-orreal-innovation en http://www.aede.es/hitos/libroblanco/

Deloitte, 2015. Deloitte Mobile Consumer Survey. Principales conclusiones en España.

Estudio de Comunicación (2013). Papel o Web: enemigos o aliados. [En línea]. Disponible en http://www2.deloitte. com/content/dam/Deloitte/es/Documents/tecnologia-media-telecomunicaciones/Deloitte_ES_TMT_ConsumoMovil-2015.pdf

Fundación Telefónica. La Sociedad de la Información en España 2014. [En línea]. Disponible en http://www. sodercan.es/wp-content/uploads/sites/4/2015/06/TELEFONICA-LA-SOCIE-

http://www.mobilemarketer.com/cms/ news/software-technology/15383.html

http://hubpages.com/technology/Aug mented-Reality-in-Newspapers-Technology-and-Uses
DAD-DE-LA-INFORMACI\%C3\%93N-ENESPA\%C3\%91A-2014.pdf

Gartner's 2013 Hype Cycle for Emerging Technologies Maps out Evolving Relationship Between Humans and Machines. [En línea]. Disponible en: http://www.gartner.com/newsroom/ id/2575515

La encrucijada de la prensa de pago. Diario de Sevilla, 24 de junio de 2013. [En línea] Disponible en http://www.diariodesevilla.es/article/sociedad/1551384/ la/encrucijada/la/prensa/pago.html

Satisfaction questionnaries. [En línea]. Disponible en www.usability.serco.com/ trump/resources/standards.htm 